\title{
A NEIGHBORHOOD ANALYSIS OF PUBLIC LIBRARY USE IN NEW YORK CITY ${ }^{1}$
}

\author{
Andrea C. Japzon ${ }^{2}$ and Hongmian Gong ${ }^{3}$
}

The use of 200 public libraries in New York City was analyzed according to their neighborhood characteristics. In addition to demographic, economic, and cultural factors traditionally considered, the social and spatial interactions within a neighborhood were related to public library use. Correlation and regression analyses were implemented for all the libraries. The research found that traditional factors are not enough to explain public library use, especially in a cosmopolitan area such as New York City. Social connections and racial diversity and integration stimulate public library use. Based on these findings, suggestions were made for improving the underutilized library branches in disadvantaged neighborhoods.

\section{Introduction}

In urban neighborhoods in the United States, public libraries often exist alongside schools and churches. They serve an important purpose in neighborhoods by offering a public space for individuals to meet formally and informally. Neighborhood public libraries are important not only for what they provide but also because they are places to obtain information through the use of books and access to the Internet. This is especially valuable in economically disadvantaged neighborhoods where such resources are scarce [1-2]. In its efforts to protect the First Amendment and provide free and open access to information, the public library has been commonly proclaimed to be a cornerstone of democracy [3]. Given the significance

1. We wish to acknowledge financial support from the City University of New York PSC-CUNY Research Award Program and the Society of Woman Geographers New York Group.

2. Drexel University, College of Information Science and Technology, 3141 Chestnut Street, Philadelphia, PA 19104; E-mail andrea.japzon@drexel.edu.

3. Assistant professor, Department of Geography, Hunter College of City University of New York, 695 Park Avenue, New York, NY 10021; Telephone 212-772-4658; Fax 212-772-5268; E-mail gong@hunter.cuny.edu.

[Library Quarterly, vol. 75, no. 4, pp. 446-463]

(C) 2005 by The University of Chicago. All rights reserved. 0024-2519/2005/7504-0003\$10.00 
of the information age, especially in technologically advanced countries such as the United States where information access becomes ever more critical, public library use is an important subject to study at the neighborhood level [4].

Public library use has traditionally been studied at state and national levels, highlighting the demographic, economic, and cultural characteristics of library users [5-7]. Surveys such as the Public Library Inquiry in 1948, the National Household Education Survey in 1991 and 1996, and the 1998 Gallup survey all found that the typical public library users were white, middle class, and well educated $[6,5]$. While these types of general surveys are important, many important questions about public library use remain unaddressed. For example, why are so many poor and less educated blacks and Hispanics not using public libraries from which they can benefit the most? What kind of effect do neighborhoods have on the public library use by these disadvantaged groups? What could be done to increase the participation of these disadvantaged groups in public library use? The traditional studies at aggregated levels do not allow an in-depth analysis of these issues. This research examines public library use within the neighborhood of which it is a part and investigates the relationship between public library use and neighborhood characteristics that extend beyond race, class, and education. Public library use is related to the social interaction of the residents within a neighborhood. How social segregation may hinder the use of public libraries by the disadvantaged groups is examined. By adding social and spatial perspectives into the study, we hope to contribute to a better understanding of public library use. Suggestions are made for improving the vitality of underutilized libraries in poor neighborhoods, which, in turn, will have positive effects on the neighborhoods, including access to information resources, resident participation, and neighborhood regeneration.

The three public library systems that serve the five boroughs in New York City are made up of 200 neighborhood branches. About one-third of these branches were built at the turn of the twentieth century with Carnegie funds [8]. Despite the guiding spatial philosophy of these branches to maximize their spatial accessibility, some branches, especially in poor Hispanic and black neighborhoods, are utilized much less than others [8]. This disturbing fact sparked our interest in conducting this research. In addition, we chose to study the public library systems in New York City because the city has a long history of immigration and the most diverse population in the United States. This study compares the findings about library users in a cosmopolitan area such as New York City to the findings from the traditional library studies. 
Literature Review

Despite the fact that library use among adults increased almost threefold between 1948 and 1991, Jim Scheppke pointed out that there is still a "long way to go for diversity" [6, p. 36]. The 1991 National Household Education Survey revealed that the majority of Hispanics (62 percent) and African Americans (58 percent) did not use libraries at all in 1990. While the 1948 Public Library Inquiry reported that the very wealthy and the very poor did not use libraries very much, the 1991 survey clearly and simply shows that public library use is positively correlated with income levels. Similarly, public library use rises with the level of education. The 1948 survey revealed that while 71 percent of college-educated adults were reported as library users, the percentage for adults with less than a high school education was only 17 percent. The 1991 survey showed that library use by children whose parents had less than a high school education was much lower than that of children whose parents had graduate or professional degrees. The relationship between public library use and demographic, economic, and cultural characteristics of the users is also discussed in other studies in library science journals $[9,5]$.

Another factor often examined in traditional studies of public library use is the spatial accessibility of a library, especially when siting a new library or relocating an underutilized old library [8, 10-12]. Christie Koontz studied six urban library systems in the United States and concluded that the location of libraries has a long-term effect on library use and cannot be treated in a cursory or descriptive manner. She recommended building a site-specific model for library location decision making based on knowledge of the estimated geographic range of the library market area and the characteristics of the people living within the area [9]. Nathaniel Obokoh and Samuel Arokoyu applied Walter Christaller's central-place theory to the study of a public library in Nigeria and found the travel time and transport costs from library users' residences to be the main predictive variables for the frequency of their library usage [12]. Central-place theory is a location theory in geography explaining the location of consumer services such as library service. The concepts of range (the distance people travel to obtain a service) and hexagonal market area in central-place theory have often evolved into travel time of library users, distance between libraries, or size of the library market area in the studies of library accessibility [13, 9].

While the demographic, economic, and cultural characteristics of library users and the spatial accessibility of libraries to the users are all important in understanding public library use, the social and spatial interactions were ignored in traditional studies. These interactions are the essence and spirit 
of urban neighborhoods of which libraries are a part and to which the libraries serve. In this research, we take social and spatial interactions within neighborhoods into consideration, in addition to the traditional factors studied. There is rich literature on neighborhoods, social capital, and social segregation, which could be applied to the studies of public library use.

Although there are many definitions of "neighborhood" (for examples, see [14-16]), there is a consensus that it is a geographical or spatial entity with boundaries. All of a neighborhood's attributes work together to give the neighborhood an identity, although some attributes are more important than others in doing so. A recent article by George Galster on the nature of a neighborhood highlighted ten major attributes, which included demographic, environmental, proximal, political, and social-interactive characteristics [14]. Because these attributes vary in different geographical scales across urban space, neighborhoods could be demarcated according to the particular neighborhood attributes of interest [14]. Applying this to our library research, we define the neighborhoods in New York City based on the market areas of the libraries and study only those attributes expected to influence the public library use in the neighborhoods.

Among the many attributes in neighborhoods, social and spatial interactions are often regarded as important attributes. They are sometimes used to define a neighborhood as "a limited territory within a larger urban area, where people inhabit dwellings and interact socially" [17, p. 13] or a geographic unit "within which certain social relationships exist" [18, p. 15]. In recent literature, the importance of social and spatial interactions to neighborhoods can be seen from a surge of research on the influence of social capital and social segregation on neighborhoods [14-16, 19].

Social capital refers to connections among individuals, such as social networks, norms of reciprocity, and social trust, that facilitate coordination and cooperation for mutual benefit [20-21]. Researchers have found that high levels of social capital produced more successful outcomes in programs on education, unemployment, urban regeneration, and crime control $[20,22]$. These positive effects come from voluntary participation of a large number of people in civic activities such as voting, being associated with nonprofit organizations, attending church, league bowling, and so on.

In contrast to social connections, social segregation is a spatial expression of social inequality and social exclusion [23]. It results from physical as well as social distance. In his analysis of segregation by class and ethnicity in Swedish cities, Roger Andersson argued that physical distance is not all that is keeping certain individuals from the full complement of society's opportunities [24]. Individuals from neighborhoods of concentrated poverty and racial segregation are often socially distant from cultural endeavors. In these neighborhoods, various problems such as high crime rates, 
low participation in education, and lack of employment opportunities are common [25]. Individuals are less likely to receive the education or exposure necessary to feel that they are part of general society.

Furthermore, multidimensional problems in neighborhoods of concentrated poverty and racial segregation often reinforce each other and create additional negative effects on the local residents. Research outcomes so far provide modest support to this thesis of neighborhood effects [25]. Nick Buck suggested that the neighborhood effects might appear as nonlinear associations between neighborhood characteristics and some outcomes. For example, "things may be distinctively different in the worst areas, on any measure, as compared with moderately poor areas" because of the neighborhood effect [19, p. 2257]. In his study of neighborhood effects on social exclusion, Buck found evidence of the nonlinear effect.

Related to library research, we believe that strong social and spatial interactions within a neighborhood facilitate public library use. In contrast, neighborhoods of concentrated poverty and racial segregation are disconnected from the benefits of mainstream society, such as quality public libraries. These neighborhoods have not had the experiences that would make using public libraries significant in the lives of the residents. We expect that these neighborhoods in New York City will have much lower public library use than others.

\section{Methodology and Data}

Correlation and regression analyses are adopted to study the impact of neighborhood characteristics on New York City public library use. The bivariate correlation analyses are used to explore the relationship between public library use and education, income, and racial factors in neighborhoods. The emphasis of these correlation analyses is on comparing these relationships with findings from previous studies. The multivariate regression analysis studies all these neighborhood characteristics together and evaluates their influences on public library use.

Public library use is the dependent variable in the analyses. There could be many ways of measuring public library use. Public libraries provide an array of services to neighborhood residents, for example, a place to sit, programs to attend, reference questions to be answered, materials to be lent, computers and books to be used on site, and so forth. However, most of these services are difficult to quantify because the means of counting them are not yet standardized, except for library circulation, which is systematically recorded. It should be noted that research indicates that libraries serving lower-income and minority communities have a high level of in-library use of library resources [26]. With this caveat in mind, library 


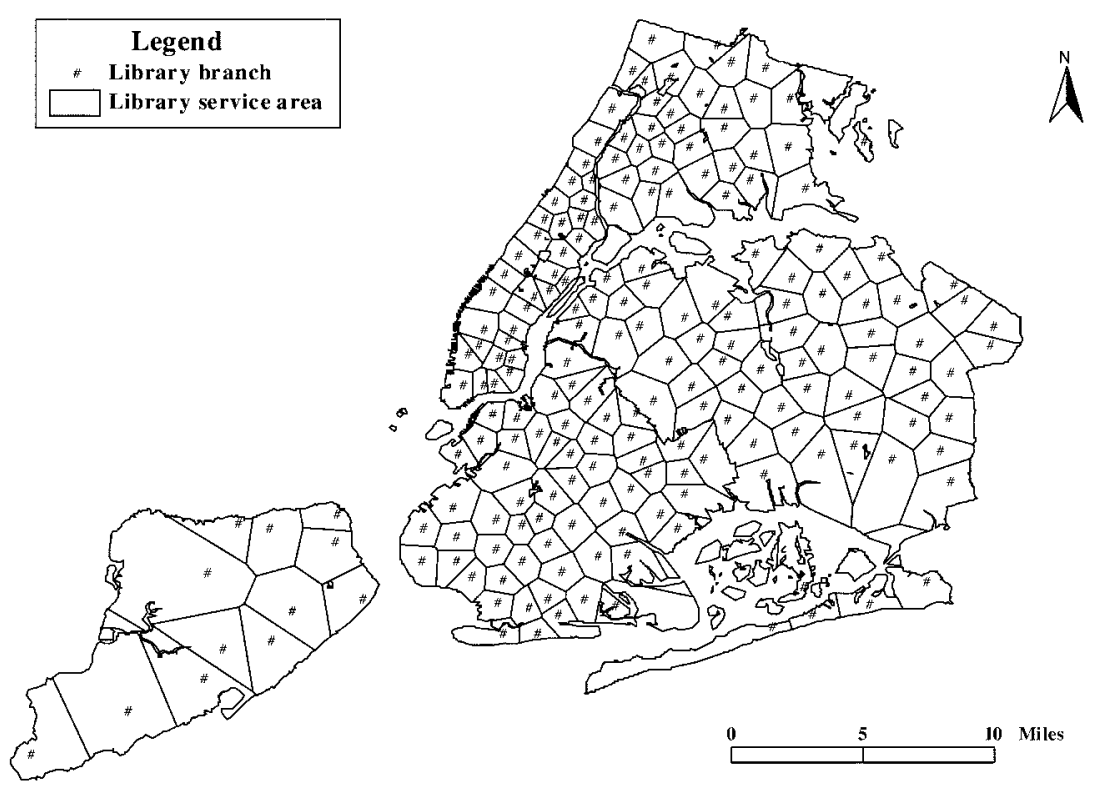

FIG. 1.-Library branches and library service areas in New York City

circulation is indicative of the level at which the library's resources are being used. For the statistical analyses in this research, library circulation, or the number of materials lent to users, is used to represent public library use. The circulation statistics for fiscal year 1998-99 were obtained for all 200 library branches in New York City.

Because these 200 branches provide similar library services, their service areas were defined by creating a Thiessen polygon around the location of each branch. Any point within a Thiessen polygon, or the service area of a branch, is closer to that branch within the polygon than to any other branch. This is based on the assumption in central-place theory that a consumer patronizes the closest central place, or library branch, in the case of this study. This assumption may not be appropriate today in many U.S. cities where people rely primarily on automobiles for travel. In New York City, however, the assumption is reasonable because most library users walk from home to library branches. According to our recent survey of 251 library users in Manhattan, Queens, and the Bronx, three-fourths of the library users walked, rather than drove or took subways or buses, to the nearest library branches.

The 200 Thiessen polygons for the branches were created in ArcInfo, a geographical information system (GIS) software (fig. 1). Defining these library service areas serves three purposes in this study. First, the library 
service areas become the basic spatial units for the statistical analyses. Data available in other spatial units such as census tracts were apportioned into each library service area based on the area proportions of these census tracts contained within each library service area. This is also done in the GIS software with an assumption that these data are evenly distributed within the census tracts. ${ }^{4}$ Second, the size of these library service areas is used to represent the spatial accessibility of the library branches in the statistical analyses, as some previous studies have done. The smaller the size of a library service area, the more accessible the library branch would be to the residents in the area and vice versa. Third, these library service areas are used to represent neighborhoods for the purpose of this study.

Most data describing neighborhood characteristics, or the explanatory variables, come from the 2000 census. Total population, race, median household income, and educational attainment for the population twentyfive years of age and older for each of the 2,217 census tracts in New York City were obtained from Census 2000 Summary File 3 [27]. Racial data include non-Hispanic white, black, and Asian of a single race. Hispanic of any race is listed as a separate variable in this study. Other races or more than one race were combined into the last racial variable because of their small populations. Median household income comes from the census in sixteen levels ranging from less than $\$ 10,000$ to more than $\$ 200,000$. Educational attainment for the adult population (used throughout this article to represent the population twenty-five years of age and older) includes less than ninth grade, ninth to twelfth grade without a diploma, high school graduate, some college without a degree, associate's degree, bachelor's degree, and graduate, professional, or $\mathrm{PhD}$ degree. These variables in census tracts were apportioned and aggregated into library service areas, as described above, and were then weighted by their totals (such as total sample households for the household income variables) in the library service areas for analyses.

In addition to these racial, economic, and cultural characteristics, variables representing social and spatial interactions, in the form of social capital and social segregation, are also included as explanatory variables. In Robert Putnam's monumental studies of social capital in the United States, he used political, civic, and religious participation, as well as workplace and informal social connections, to measure civic engagement and

4. This assumption has to be made to unify all variables into a consistent spatial unit for statistical analyses. In densely populated New York City, this assumption is not too far from the reality. For example, there are 2,217 census tracts in New York City, about eleven census tracts in each of those 200 library service areas in fig. 1 . These census tracts are very small in land area and could be considered more or less homogeneous for the purpose of this study. Besides, this assumption only applies to census tracts that fall into two or more library services areas. 
social capital [20-21]. Data on these activities for New York City are difficult to obtain for the statistical analyses. Number of nonprofit organizations per capita, one of the social capital indicators in Putnam's studies [20-21], was therefore used as the surrogate for social capital. With the use of a surrogate, the research explored the possibility of a relationship between social capital and public library use in New York City, rather than proving an exact relationship. Data on the number of nonprofit organizations by ZIP code in New York City were obtained from SuperPages.com, Verizon's online telephone directory [28]. They were then converted into data by library service area and weighted by the neighborhood population to derive the number of nonprofit organizations per capita.

To measure social segregation in neighborhoods, the racial segregation index and income segregation index were calculated using David Wong's multigroup spatial index of segregation, $\mathrm{SD}(\mathrm{m})$ [29]. For each library service area, the census tracts within or contiguous to the library service area were selected in the ArcView GIS software, and the racial and income indices were then calculated for that area. The $\mathrm{SD}(\mathrm{m})$ index ranges from zero to one, where zero indicates no segregation, and one, perfect segregation. It is chosen for this study because of its two advantages over other segregation indices. One advantage is that the $\mathrm{SD}(\mathrm{m})$ index allows the input of more than two groups in the calculation, which is essential in studying a cosmopolitan area such as New York City. In this study, four racial groups (white, black, Hispanic, and Asian) were included in calculating the racial segregation index and sixteen income groups in the income segregation index. Another advantage is that the $\mathrm{SD}(\mathrm{m})$ index takes into account not only the racial (or income) composition within a census tract, as other segregation indices typically do, but also the spatial interaction of neighboring census tracts. The $\mathrm{SD}(\mathrm{m})$ index indicates higher segregation when similar census tracts locate together than when different census tracts locate together because the latter allows more mixing of different groups of people across census tract boundaries. The racial and income segregation indices represent the sociospatial aspect of a neighborhood by measuring the racial and income compositions within census tracts and the spatial arrangement of the census tracts within and around the neighborhood. They are different from the racial or income variables discussed earlier.

Results of Statistical Analyses

Correlation Analysis

Pearson correlations between circulation per capita and racial, income, education, and social and spatial variables in New York City were first 
TABLE 1

Pearson Correlation of Circulation Per Capita and Racial Variables

\begin{tabular}{lcc}
\hline \hline Race & Correlation & Significance \\
\hline Hispanic (of any race) & $-.355^{* *}$ & .000 \\
White alone (non-Hispanic) & $.438^{* *}$ & .000 \\
Black alone (non-Hispanic) & $-.419^{* *}$ & .000 \\
Asian alone (non-Hispanic) & $.480^{* *}$ & .000 \\
Others & -.045 & .526 \\
\hline
\end{tabular}

Source.-U.S. Census Bureau, 2002 [27].

** Significant at the .01 level.

examined, and results are listed in tables 1-4. The main purpose of these bivariate analyses is to compare these correlations in New York City with those revealed in traditional library studies. Out of the five racial variables (table 1), the percentages of the population made up of Asians and whites had significant positive correlations with circulation per capita, while the percentages of the population made up of blacks and Hispanics had significant negative correlations. The percentage of the population in other races or more than one race had no significant correlation with circulation per capita. Generally speaking, the correlations between circulation per capita and the racial variables in New York City support the findings from previous library studies. It may be a little surprising that the strongest correlation with circulation per capita came from the Asian variable because most previous studies did not examine the Asian population separately. This strong correlation does match the finding about the Asian population in Koontz's study and librarians' observations of heavy use of public libraries by Asians [9, 26].

The correlations between circulation per capita and the sixteen income variables show an interesting pattern (table 2). Circulation had the strongest negative and significant correlation with the percentage of households with less than $\$ 10,000$ annual income. The negative correlation coefficient declines as household income increases until the correlation turns positive for the $\$ 35,000-\$ 39,999$ income group. The positive correlation becomes significant at the 0.01 level and climbs up to the strongest at the $\$ 75,000-\$ 99,999$ income group. Then, the positive correlation coefficient gradually declines and becomes insignificant for the percentage of households with $\$ 200,000$ or more annual income. This pattern corroborates the previous finding that the very poor and very wealthy do not use public libraries as much as the middle-income class. The households with $\$ 200,000$ or more annual income in New York City do not use public libraries much because they can better afford buying books and having Internet access at home. However, the significant negative correlation for households with 
TABLE 2

Pearson Correlation of Circulation Per Capita and Household InCOME VARIAbles

\begin{tabular}{lcc}
\hline \hline Income Variable $(\$)$ & Correlation & Significance \\
\hline Less than 10,000 & $-.435^{* *}$ & .000 \\
$10,000-14,999$ & $-.309^{* *}$ & .000 \\
$15,000-19,999$ & $-.315^{* *}$ & .000 \\
$20,000-24,999$ & $-.282^{* *}$ & .000 \\
$25,000-29,999$ & $-.319 * *$ & .000 \\
$30,000-34,999$ & $-.249 * *$ & .000 \\
$35,000-39,999$ & .051 & .477 \\
$40,000-44,999$ & $.281^{* *}$ & .000 \\
$45,000-49,999$ & $.262^{* *}$ & .000 \\
$50,000-59,999$ & $.380^{* *}$ & .000 \\
$60,000-74,999$ & $.398^{* *}$ & .000 \\
$75,000-99,999$ & $.461^{* *}$ & .000 \\
$100,000-124,999$ & $.399^{* *}$ & .000 \\
$125,000-149,999$ & $.381^{* *}$ & .000 \\
$150,000-199,999$ & $.275^{* *}$ & .000 \\
200,000 or more & .071 & .320 \\
\hline
\end{tabular}

Source.-U.S. Census Bureau, 2002 [27].

** Significant at .01 level.

less than $\$ 35,000$ annual income, especially the ones with less than $\$ 10,000$, indicates that the poor households are socially distant from public libraries.

The time-allocation theory as related to public library use by Nancy Van House supports this finding. The cost for using a public library is generally measured in time: traveling and queuing for services. For wealthier individuals, time and money is saved by paying for materials rather than borrowing them, because this is a more efficient use of time. For lower-income individuals, the ability to pay for substitutes for time is very difficult; child care is the prime example of this. In this sense, the lack of time is a likely inhibitor of library use for lower-income populations [30].

The positive relationship between library use and education is quite obvious in table 3 . Circulation per capita had significant negative correlations with the percentages of the adult population with less than nine years of education or with nine-twelve years of education. The correlation turns positive but insignificant for the percentages of the adult population with a high school diploma, some college education, or an associate's degree. For the percentages of the adult population with bachelor's, graduate, professional, or PhD degrees, the correlations were significantly positive. The relationship between library use and education in New York City closely matches that reported in previous library studies.

The result of the correlation analysis for the social and spatial variables 
TABLE 3

Pearson Correlation of Circulation Per Capita and Education Variables

\begin{tabular}{lccc}
\hline \hline Education Variable & Correlation & Significance & $\begin{array}{c}\text { Percentage of Total } \\
\text { Population }\end{array}$ \\
\hline Less than ninth grade & $-.280^{* *}$ & .000 & 11.99 \\
Between ninth and twelfth grade & $-.400^{* *}$ & .000 & 15.73 \\
High school graduate & .120 & .091 & 24.43 \\
Some college & .051 & .476 & 15.19 \\
Associate's degree & .095 & .183 & 5.24 \\
Bachelor's degree & $.243^{* *}$ & .001 & 15.82 \\
Graduate/professional/PhD degree & $.176^{*}$ & .013 & 11.60 \\
\hline
\end{tabular}

Source.-U.S. Census Bureau, 2002 [27]

* Significant at .05 level.

** Significant at .01 level.

is mixed (table 4). The size of a library service area, representing the spatial accessibility of a library branch, did not have a significant correlation with the circulation. Although this linear correlation was not statistically significant, the negative sign of the correlation coefficient (table 4) indicates that circulation per capita was higher in a library branch with a smaller service area and better spatial accessibility, which is consistent with the findings in previous library studies. The number of nonprofit organizations per capita and the racial and income segregation indices had significant correlation with circulation per capita at the 0.01 level.

Regression Analysis

Although the correlations between the circulation per capita and the racial, economic, and educational variables in tables 1-3 match the findings in previous library studies, these simple bivariate correlation analyses are not the best way of examining the causal effects of these variables on circulation per capita. A multiple regression analysis is better for two technical reasons. One is that many of the racial, economic, and educational variables are highly correlated themselves. For example, the percentage of the population that is white was highly correlated with the percentage of the adult population with a bachelor's degree (a correlation coefficient of 0.641) and with the percentage of households with income between $\$ 75,000$ and $\$ 99,999$ (a correlation coefficient of 0.630 ). Without a multivariate analysis, it would be difficult to pinpoint which of these racial, economic, and educational variables had the most direct effect on circulation per capita. Another reason is that the relationship between circulation per capita and these variables may not be linear as measured in the correlation in tables $1-4$. For example, although circulation per capita and the size of the library service area did not have a significant correlation, as shown in table 4, 
TABLE 4

Pearson Correlation of Circulation Per Capita with Social and/or Spatial Variables

\begin{tabular}{lcc}
\hline \hline Social/Spatial Variable & Correlation & Significance \\
\hline Library service area & -.088 & .218 \\
Income segregation & $-.226^{* *}$ & .001 \\
Racial segregation & $-.187^{* *}$ & .008 \\
Nonprofit organizations per capita & $.358^{* *}$ & .000 \\
\hline
\end{tabular}

Sources.-SuperPages.com [28]; U.S. Census Bureau, 2002 [27].

** Significant at .01 level.

these two variables in natural logarithm did significantly correlate with each other at the 0.01 level. A double-log regression analysis could capture this kind of nonlinear relationship. Most important, a multiple regression analysis allows all variables to be studied together from a neighborhood perspective.

The dependent variable in the multiple regression was circulation per capita. Variables in tables 1-4 were used as explanatory variables. All these variables were taken natural logarithm before the regression was performed in an IBM mainframe using software SPSSX. A stepwise method was used with PIN (probability of $F$ to enter) set as 0.1 , POUT (probability of $F$ to enter) as 0.11 , and tolerance as 0.3 . The regression is significant with an $R^{2}$ of 61 percent and an adjusted $R^{2}$ of 59 percent. Eight explanatory variables entered the regression equation and are listed in table 5 in a descending order of the absolute values of their $\beta$ (standardized) coefficient. There is no significant violation of statistical assumptions in the regression, thus yielding a reliable estimation of the relationship between the dependent variable and the eight explanatory variables.

Three of the five racial variables in table 1 were significant at the 0.01 level in the regression (table 5). The variable ASIAN, representing the percentage of the population that is Asian in natural logarithm, had the strongest and positive influence on circulation per capita. The percentage of the population that is white (WHITE) had the third highest and positive standardized coefficient, while the percentage of the population that is Hispanic (HISPANIC) had the fifth highest but negative coefficient. The percentage of the population that is black did not enter the regression equation but not because its negative coefficient was not significant. It would have been significant at the 0.05 level. It was because this variable would have brought down the tolerance of the variables already in the equation, an indication that it highly correlates with some of the eight significant explanatory variables. Overall, race plays an important role in the variation of public library use across neighborhoods in New York City.

The percentage of the adult population with a high school diploma in 
TABLE 5

Regression Analysis of the Public Library Circulation in New York City

\begin{tabular}{lcccrc}
\hline \hline Explanatory Variable & $\beta$ Coefficient & SE $\beta$ & Tolerance & $T$-Value & Significance \\
\hline ASIAN & .3319 & .0652 & .4837 & 5.087 & .0000 \\
EHIGH & .3286 & .0532 & .7267 & 6.173 & .0000 \\
WHITE & .2916 & .0707 & .4116 & 4.122 & .0001 \\
INCLT10 & -.1802 & .0793 & .3273 & -2.271 & .0243 \\
HISPANIC & -.1707 & .0605 & .5633 & -2.824 & .0052 \\
NPORG & .1526 & .0511 & .7879 & 2.986 & .0032 \\
AREA & -.1487 & .0554 & .6719 & -2.685 & .0079 \\
RSEG & -.0880 & .0466 & .9473 & -1.888 & .0605 \\
\hline
\end{tabular}

NotE.-Only the explanatory variables that were entered in the equation of the stepwise regression are listed here. $R^{2}=61 \%$; adjusted $R^{2}=59 \% ; F=36.8210 ;$ significance $F=.0000$.

its natural logarithm (EHIGH) had the second highest and positive standardized coefficient in the regression. It had a high tolerance of 0.7267 too (table 5), indicating that it was quite independent from other explanatory variables. Other education variables did not enter the equation, primarily because they were highly correlated with variables already in the equation. For example, the percentage of the adult population with a bachelor's degree correlates highly with the variable WHITE, as described earlier. By examining the relationships between public library use and various educational attainments within the context of other neighborhood characteristics, we find the causal relationship with high school graduates (EHIGH) was more significant than the one with the college-educated population.

The significant causal relationship between public library use and the percentage of the adult population with a high school diploma has not been discussed much in previous library studies. Most of these studies applied only linear bivariate correlation analyses. When the correlation between public library use and education attainment was discussed, the focus was very often on the correlation with college-educated adults rather than a much lower correlation with high school graduates. Considering the improvement of the regression analysis over the correlation analysis in this research, we believe that had these previous library studies used nonlinear multiple regressions to study public library use, the causal relationship with high school education would have been obvious. One previous study did use multiple (but linear) regression analyses to model the public library use in six urban library systems in the United States [9]. The significant relationship with the percentage of the adult population with a high school diploma was reported in one urban library system.

After all, this finding about public library use and high school graduates is statistically reliable in this research, as well as reasonable. The finding 
reveals that reducing the high school dropout rate and therefore increasing the percentage of the adult population with a high school diploma will increase the public library use in New York City. Because high school graduates make up the largest group-about a quarter (24.43 percent) of the New York City residents-among all education attainments (table 3), this finding also implies a great potential for improving public library use by involving a higher percentage of high school graduates.

Similar to the education variables, all but one income variable entered the equation. Percentage of households with an income less than $\$ 10,000$ had a negative and the fourth-highest coefficient in the regression. This means that the concentration of the lowest-income households in a neighborhood had an exponential negative effect on the use of its library branch. It is a nonlinear effect that is not significant in a neighborhood with a concentration of households in higher income categories. This finding provides one more point of evidence to support the thesis of neighborhood effects in the literature.

Three of the four social and spatial variables in table 4 were significant in the regression. They are the number of nonprofit organizations per capita (NPORG), size of library service area (AREA), and racial segregation index (RSEG). The first two were significant at the 0.01 level, while the third was significant at the 0.1 level. The income segregation index was not significant. The three significant variables had the expected relationships with circulation per capita, meaning that public library use was higher in a neighborhood with better spatial accessibility, stronger social connections in the form of nonprofit organizations, and more racial diversity and integration. These variables had high tolerances also, explaining the variation in public library use from dimensions different from race, income, and education.

\section{Conclusion and Discussion}

This research explores factors in addition to race, class, education, and spatial accessibility considered in traditional library studies that affect public library use in New York City. The neighborhood characteristics such as social and spatial interactions were found to be important in affecting public library use in the regression analysis, thereby adding a sociospatial dimension to the library use studies. The neighborhood analysis approach used in this research is also an improvement on the way that public library use was traditionally studied. It emphasizes the interaction of various neighborhood characteristics and its joined influence on public library use, rather than the influence of each single demographic, economic, cultural, or spatial factor. 
The analyses in this research confirm the importance of the traditional factors such as neighborhood characteristics in terms of race, income, and education and the spatial accessibility of the branch location. Race is an especially important factor on public library use as three racial variables enter the regression equation. Generally speaking, neighborhoods with high percentages of populations of Asians and whites and low percentages of populations of Hispanics and blacks have high public library use. Education is also an important factor as an education-attainment variable (the percentage of the adult population with a high school education) is the second strongest predictor of public library use in New York City. Education has long been considered one of the most important predictors of library use [5-7,9]. This is because educated individuals are more likely to use the library as well as to be more efficient in their use of it, because through the education process, individuals learn how to use libraries and information [30].

In addition, this research found that the national trend of a typical public library user being white, middle class, and well educated does not give a complete picture of public library use. In New York City, white, middle class, and well educated are three highly correlated variables describing only one group of public library users. Asians, with their significant presence in New York City, are another major group of public library users, and the percentage of the population that was Asian was the most influential variable in the regression. The percentage of the adult population with only a high school education was the second most important variable in the regression, indicating a great potential to improve public library use in New York City. This result differs from previous library surveys that indicate college education as a significant predictor of library use. Reducing high school dropout rates and attracting high school graduates to the libraries can substantially improve public library use.

In terms of the underutilization of library branches in disadvantaged neighborhoods, the findings from the statistical analyses provide insights for improvement. First, disadvantaged neighborhoods can improve the use of their library branches by targeting residents with high school diplomas. The improvement on public library use in these neighborhoods should be focused more on increasing the number of library users rather than increasing the frequency of existing library users' visits. In a disadvantaged neighborhood, it may be difficult to find a large group of residents with a higher education, but not residents with only a high school education. The large group of residents with high school diplomas in disadvantaged neighborhoods could potentially become library users.

Second, the branches in disadvantaged neighborhoods should be maintained to reflect the neighborhood characteristics both in appearance and in library materials. Materials that are suitable for healthy neighborhoods 
may not hold much interest or be relevant in disadvantaged neighborhoods. If collections in library branches are too centralized and universally developed, the information or reading interests of disadvantaged groups are likely to be neglected. As demonstrated in the correlation and regression analyses in New York City, there is a positive relationship between public library use and social interaction. When a library branch is integrated to be part of the neighborhood and provides a public place for social interaction within the neighborhood, the neighborhood will likely support the work of the branch.

Third, library branches in disadvantaged neighborhoods should get higher budgets than are proportional to their circulation figures. The rationale is that the relationship between circulation and neighborhood characteristics is nonlinear, as demonstrated in the loglinear regression analysis. For example, a high percentage of Hispanics and a high percentage of households with less than a $\$ 10,000$ annual income in a disadvantaged neighborhood have an exponential negative impact on the circulation per capita of the library branch. In these neighborhoods, extra efforts and, therefore, extra funds are necessary to increase the circulations of the library branches. With the current funding system of budgets being proportional to circulation figures, the self-perpetuating cycles of underutilization in disadvantaged neighborhoods will continue. Greater funding is needed to break these cycles. The extra money could be used to purchase more library materials, for outreach programs to attract people to the branches, and to extend the hours of operation to accommodate working people.

Also, public library systems should seek to standardize and account for in-library use of resources. As mentioned earlier, public libraries in disadvantaged neighborhoods tend to use library resources on site more so than off site. By defining and collecting a diverse set of use figures, public library systems can more accurately assess the level of support needed for all library services and resources for each community served [26]. By expanding the measurement of library usage beyond circulation counts, the reasons to support public libraries in disadvantaged neighborhoods will expand as well.

In the short term, the shift in budget into disadvantaged neighborhoods may reduce the efficiency of the New York City library systems because the same amount of money produces higher circulations in healthy neighborhoods. But it brings social justice to the disadvantaged neighborhoods. The Public Library Mission Statement and Its Imperatives for Service advises that public libraries in disadvantaged neighborhoods target the unique needs of the community through the resources selected and the services offered. This document calls for public libraries to respond to the need to make information easily accessible to those that have been previously excluded 
from library services through "lack of education, lack of language facility, ethnic or cultural backgrounds, age, physical or mental handicaps, and apathy" [31, p. 7]. For the long term, a beneficial relationship between public library use and the human, economic, and cultural capital in disadvantaged neighborhoods could be established to improve and sustain the use of the library branches.

\section{REFERENCES}

1. Sanyal, B. "From Dirt Road to Information Superhighway: Advanced Information Technology (AIT) and the Future of the Urban Poor." In Cities in the Telecommunication Age, edited by J. Wheeler, Y. Aoyama, and B. Warf. New York: Routledge, 2000, 143-60.

2. U.S. Department of Commerce. Falling Through the Net: Toward Digital Inclusion. 2000. http: //www.ntia.doc.gov/ntiahome/fttn00/contents00.html.

3. Lees, L. "Ageographia, Heterotopia, and Vancouver's New Public Library." Environment and Planning D: Society and Space 15 (1997): 321-47.

4. Castells, M. The Information City. Cambridge, MA: Basil Blackwell, 1989.

5. Vavrek, B. "Is the American Public Library Part of Everyone's Life?" American Libraries 31 (2000): 60-63.

6. Scheppke, Jim. "Who's Using the Public Library?" Library Journal 119 (1994): 35-38.

7. Speer, T. L. "Libraries from A to Z." American Demographics 17 (1995): 48-54.

8. Freeston, R. "The Geography of Urban Public Library Development." Minnesota Libraries 25 (1978): 299-310.

9. Koontz, Christie M. "Public Library Site Evaluation and Location: Past and Present MarketBased Modeling Tools for the Future." Library and Information Science Research 14 (1992): 379-409.

10. Osiobe, S. A. "Factors Inhibiting Public Library Use." Library Review 30 (1981): 13-17.

11. Hayes, R., and Palmer, E. S. "The Effects of Distance upon Use of Libraries: Case Studies Based on a Survey of Users of the Los Angeles Public Library Central Library and Branches." Library Research 5 (1983): 67-100.

12. Obokoh, Nathaniel P., and Arokoyu, Samuel B. "The Influence of Geographical Location on Public Library Use: A Case Study from a Developing Country.” Bulletin of the Special Libraries Association Geography and Map Division 163 (1991): 30-42.

13. Hartshorn, T. A. Interpreting the City: An Urban Geography. New York: Wiley, 1992.

14. Galster, George. "On the Nature of Neighborhood." Urban Studies 38 (2001): 2111-24.

15. Forrest, R., and Kearns, A. "Social Cohesion, Social Capital, and the Neighborhood." Urban Studies 38 (2001): 2125-43.

16. Kearns, A., and Parkinson, M. "The Significance of Neighborhood." Urban Studies 38 (2001): 2103-10.

17. Hallman, H. W. Neighborhoods: Their Place in Urban Life. Beverly Hills, CA: Sage, 1984.

18. Downs, A. Neighborhoods and Urban Development. Washington, DC: Brookings Institution, 1981.

19. Buck, Nick. "Identifying Neighbourhood Effects on Social Exclusion." Urban Studies 38 (2001): 2251-75.

20. Putnam, Robert D. "Bowling Alone: America's Declining Social Capital." Journal of Democracy 6 (1995): 65-78.

21. Putnam, Robert D. Bowling Alone: The Collapse and Revival of American Community. New York: Simon \& Schuster, 2000. 
22. Purdue, D. "Neighborhood Governance: Leadership, Trust, and Social Capital." Urban Studies 38 (2001): 2211-24.

23. Morrill, R. "Racial Segregation and Class in a Liberal Metropolis." Geographical Analysis 27 (1995): 22-41.

24. Andersson, Roger. “'Divided Cities' as a Policy-Based Notion in Sweden.” Housing Studies 14 (1999): 601-24.

25. Musterd, S.; Priemus, H.; and Kempen, R. V. "Towards Undivided Cities: The Potential of Economic Revitalisation and Housing Redifferentiation.” Housing Studies 14 (1999): $573-84$.

26. Jue, D. K.; Koontz, C. M.; and Lance, K. C. "Collecting Detailed In-Library Usage Data in the U.S. Public Libraries: The Methodology, the Results, and the Impact." In Proceedings of the Third Northumbria International Conference on Performance Measurement in Libraries and Information Services. Newcastle: University of Northumbria, 2001, 175-79.

27. U.S. Census Bureau. Census 2000 Summary File 3. Washington, DC: U.S. Census Bureau, 2002.

28. Verizon. SuperPages.com. 2002. http://www.superpages.com.

29. Wong, David W. S. "Measuring Multiethnic Spatial Segregation." Urban Geography 19 (1998): 77-87.

30. Van House, Nancy A. "A Time Allocation Theory of Public Library Use." Library and Information Science Research 5 (1983): 365-84.

31. Public Library Association. The Public Library Mission Statement and Its Imperatives for Service. Chicago: ALA, 1979. 